\title{
The Hindi Pentad of V: Vijay over Diabetes
}

\section{Bharti Kalra ${ }^{1}$ Hans Raj Kalra ${ }^{2} \quad$ Navneet Aggarwal $^{3}$ Shrimant Kumar Sahoo ${ }^{4}$}

${ }^{1}$ Department of Gynaecology, Bharti Hospital, Karnal, Haryana, India

2Department of Diabetes Education, Bharti Hospital, Karnal, Haryana, India

${ }^{3}$ Department of Diabetology, DOT Centre, Gwalior, Madhya Pradesh, India

${ }^{4}$ Department of Diabetology, Global Hospital and Research Center, Mount Abu, Rajasthan, India

J Soc Health Diab 2019;7:33

Motivation of a person with diabetes is a challenging aspect of diabetes care. Persons with diabetes, and their caregivers, find it difficult to internalize the concepts of diabetes care philosophy. We share a simple, Hindi language-based model, designed in an alliterative manner, to explain the constituents of good diabetes self-care and their strength.

The proactive pentad of vijay (victory) over diabetes, as we term it, includes the five Vs: vyanjan (diet), vyayam (exercise), vichaar (stress management), vyavhaar (behavior), and vaidya anupalan (adherence to therapy). Following these five Vs can help overcome deleterious effects of virasat
Address for correspondence Bharti Kalra, MD, Department of Gynaecology, Bharti Hospital, Karnal 132001, Haryana, India (e-mail: dr.kalrabharti@gmail.com).

(genes) and vatavaran (environment) and help modify vidhi ka vidhaan (destiny) (-Fig. 1).

Thus, the pentad of Vs fosters a proactive and optimistic outlook, in a patient-centered manner. This model is concordant with the concept of metabolic karma, as it encourages actions designed to improve future outcomes. It stimulates the internal locus of control of the person with diabetes, thus encouraging active self-care and self-management. The five pointed rubric can also be used as a motivational tool for family and community members.

\section{Conflict of Interest}

None declared.

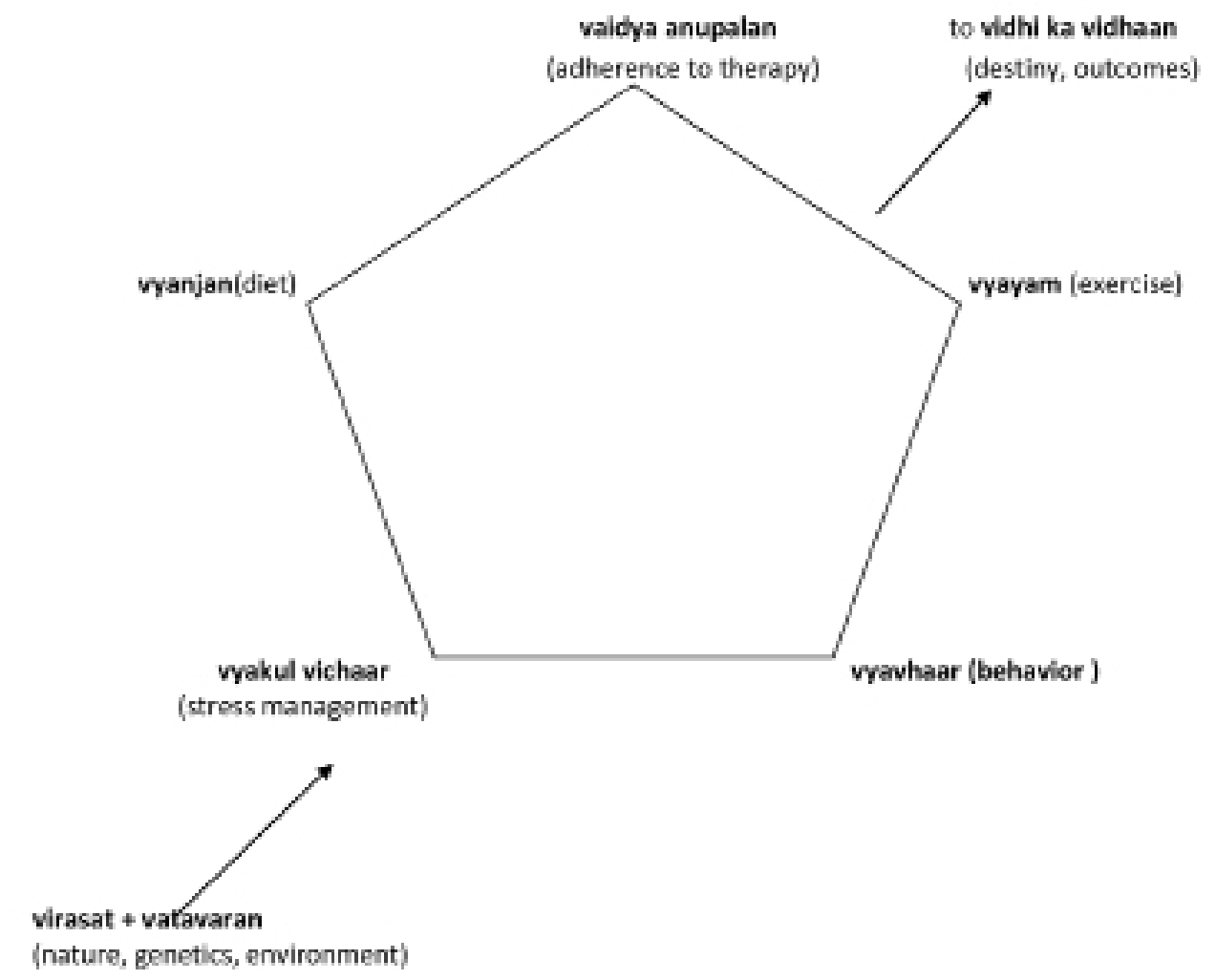

Fig. 1 The proactive pentad of Vs.

(C)2019 Novo Nordisk Education Foundation
License terms

(요 (1) $\Theta \circledast$ 